\section{International Scientific Journal Theoretical \& Applied Science}

\author{
Zaur Mazahir Mamedov \\ Doctoral student of the Department "World \\ Economy and Marketing" \\ Sumgayit State University, \\ The Republic of Azerbaijan
}

SECTION 31. Economic research, finance, innovation, risk management.

\title{
THE PERFECTION OF ORGANIZATIONAL AND ECONOMIC MECHANISMS OF INNOVATIVE ENTREPRENEURSHIP AND ITS MANAGEMENT (ON THE EXAMPLE OF THE OIL INDUSTRY)
}

\begin{abstract}
The problems of improving the organizational and economic mechanisms of innovative entrepreneurship and its management (on the example of the oil industry) arestudiedin the article. The importance of accelerating the development of innovative activities in the country, including in the oil industry, is analyzed with this purpose.The dynamics of the output of innovative products in the extractive industry in view of the oil industry in detail is analyzed.Factors that hamper the development of innovative entrepreneurship in the oil industry are considered.A number of recommendations and proposals on the problems of improving the organizational and economic mechanisms of innovation entrepreneurship and its management (on the example of the oil industry) are given

Key words: Azerbaijan, innovative entrepreneurship, organizational and economic mechanisms of innovation business management, innovative entrepreneurship in the oil industry, improvement of innovative business management system.

Language: Russian

Citation: Mamedov ZM (2017) THE PERFECTION OF ORGANIZATIONAL AND ECONOMIC MECHANISMS OF INNOVATIVE ENTREPRENEURSHIP AND ITS MANAGEMENT (ON THE EXAMPLE OF THE OIL INDUSTRY). ISJ Theoretical \& Applied Science, 12 (56): 243-249.

Soi: http://s-o-i.org/1.1/TAS-12-56-40 Doi: crossef https://dx.doi.org/10.15863/TAS.2017.12.56.40

\section{СОВЕРШЕНСТВОВАНИЕ ОРГАНИЗАЦИОННО-ЭКОНОМИЧЕСКОГО МЕХАНИЗМА ИННОВАЦИОННОГО ПРЕДПРИНИМАТЕЛЬСТВА И ЕГО УПРАВЛЕНИЕ} (НА ПРИМЕРЕ НЕФТЯНОЙ ПРОМЫШЛЕННОСТИ)
\end{abstract}

Аннотация: В статье исследованы проблемы совериенствования организационно-экономических механизмов инновачионного предпринимательства и его управление (на примере нефтяной промышленности). С этой целью анализирована важность ускорения развития инновационной деятельности в стране, в том числе в нефтяной промышленности. Подробно анализирована динамика выпуска инновационной продукции в добывающей отрасли с учетом нефтяной промышленности. Рассмотрены факторы, мешающче развитию инновационного предпринимательства в нефтяной промышленности. Дан ряд рекомендащий $u$ предложений по проблемам совершенствования организационно-экономических механизмов инновационного предпринимательства и его управления (на примере нефтяной промышленности).

Ключевые слова: Азербайджан, инновационное предпринимательство, организационно-экономические механизмы управления инновационным предпринимательством, инновационное предпринимательство в нефтяной промышленности, совершенствование системь управления инновационным предпринимательством.

\section{Introduction}

Современные тенденции развития и особенности мировой экономики интенсивно обуславливают совершенствование существующих механизмов и их обновление.
Особенно востребовано совершенствование с применением более продуктивных и эффективных инструментарий, традиционных механизмов предпринимательства и его управления, организационно-экономических 
механизмов и прочее. В условиях усиления глобальных влияний, активное применение инновационных функций и процессов с эффективной организацией инновационного предпринимательства способствует интенсификации развития национальной экономики, формирует новые источники роста экономики и помогает существенному повышению еe конкурентоспособности. Если посмотреть мировой опыт, все развитые страны добились наилучших результатов и успехов в развитии своей экономики, именно за счет активной разработки и внедрения высоких технологий, увеличения инвестиций и капитального вложения в широкое применение результатов технологических разработок и инновационных функций $[1 ; 2 ; 3]$. С этой точки зрения, 70-90 \% формирования ВВП развитых стран приходится на долю инновационной продукции [4;5]. Кроме того, оптимальное моделирование инновационного предпринимательства, его управление, совершенствование организационноэкономических механизмов способствует расширению инноватизации национальной экономики и существенному росту объема инновационной продукции в нынешнем времени $[6 ; 7 ; 8 ; 9 ; 10 ; 11 ; 12]$. К сожалению, в Азербайджане еще не достигнуты определенные успехи в развитии инновационного предпринимательства и в том числе в развитии рынка инновационных продукций, технологий. Существуют барьеры по развитию инновационных функций, предложение на инновационную продукцию находится на низком уровне и в целом организация ее управленческой системы, так как еще не создана национальная инновационная система в Азербайджане $\quad[13 ; 14 ; 15 ; 16 ; 17]$. Например, в Азербайджане всего $5 \%$ субъектов предпринимательства производит инновационную продукцию. Для сравнения, аналогичный показатель в странах Евросоюза составляет 63-66 \%, в США - 74-76 \%, в Японии 70-71 $\%$ Активное инновационное предпринимательство дает возможность интенсификации использования результатов научно-технической деятельности, различных разработок наукоемкой и инновационной продукции.

\section{Materials and Methods}

Отметим, что в Азербайджане в нынешних условиях реализуются комплексные приоритетные мероприятия и работы по исполнению поставленных задач в рамках стратегических дорожных карт по перспективному развитию национальной экономики. Основная цель проводимой работы заключается в снижении зависимости национальной экономики Азербайджана от нефтяного фактора. Однако нельзя забывать, что нефтяная промышленность за прошедшие 100150 лет являлась и по сей день является ведущей сферой промышленности и ныне выступает в качестве локомотива национальной экономики. На наш взгляд, нефтяная промышленность и в будущем долгое время будет занимать ведущие места в экономическом развитии Азербайджана и вносить свой вклад в усиление экономического потенциала на пути достижения уровня развитых стран мира. Отрадно, что в рамках реализации нефтяной стратегии заново создается материально-техническая инфраструктура нефтяной промышленности на основе высоких технологий и привлекаются многомиллиардные иностранные инвестиции. Согласно «Контракт века», подписано 30 различных соглашений с 41 нефтяными компаниями из 19 стран мира и в рамках реализации этих соглашений, общий объем вложенных инвестиций в экономику Азербайджан составляет 200 млрд. долл. США, львиная доля которых вложена в нефтяную промышленность. Однако следует подчеркнуть, что нефтяная промышленность Азербайджана остро нуждается в развитии предпринимательства, создании рыночных и инновационных предприятий. Необходимо сформировать сеть частных предприятий и компаний инновационного характера с учетом развития объема перерабатывающей сферы нефтегазовой промышленности. Как известно, в Азербайджане проводится усиленная государственная политика по развитию предпринимательства и были бы целесообразны аналогичные работы, интенсификация в нефтяном промышленности. Нуждаются в совершенствовании подходы и стратегии по расширению круга переработки с акцентом на создание современных предприятий на основе новых технологий и инновационных функций. Все эти работы могут способствовать расширению перечня экспортоориентировочных конкурентоспособных продукций и повышению экспортного потенциала с ростом объема ненефтяной экспортной продукции. Однако для этого требуется сперва обеспечить комплексный подход по созданию и развитию национальной инновационной системы, в том числе инновационной системы в нефтяной промышленности. Если обратить внимение на статистические данные, изданные официальными органами Азербайджанской Республики, то отчетливо видно, что ассортимент и объем инновационной продукции оставляет желать лучшего и находится на низком уровне.

На Рисунке 1 дан объем инновационной продукции по 2007-2016 годам в добывающей 


\begin{tabular}{|c|c|c|c|c|c|c|}
\hline \multirow{4}{*}{ Impact Factor: } & ISRA (India) & $=1.344$ & SIS (USA) & $=0.912$ & ICV (Poland) & $=6.630$ \\
\hline & ISI (Dubai, UAF & $=0.829$ & РИНЦ (Russia) & $=0.207$ & PIF (India) & $=1.940$ \\
\hline & GIF (Australia) & $=0.564$ & ESJI (KZ) & $=4.102$ & IBI (India) & $=4.260$ \\
\hline & JIF & $=1.500$ & SJIF (Morocco & $=2.031$ & & \\
\hline
\end{tabular}

промышленности, куда входит и нефтяная отрасль.

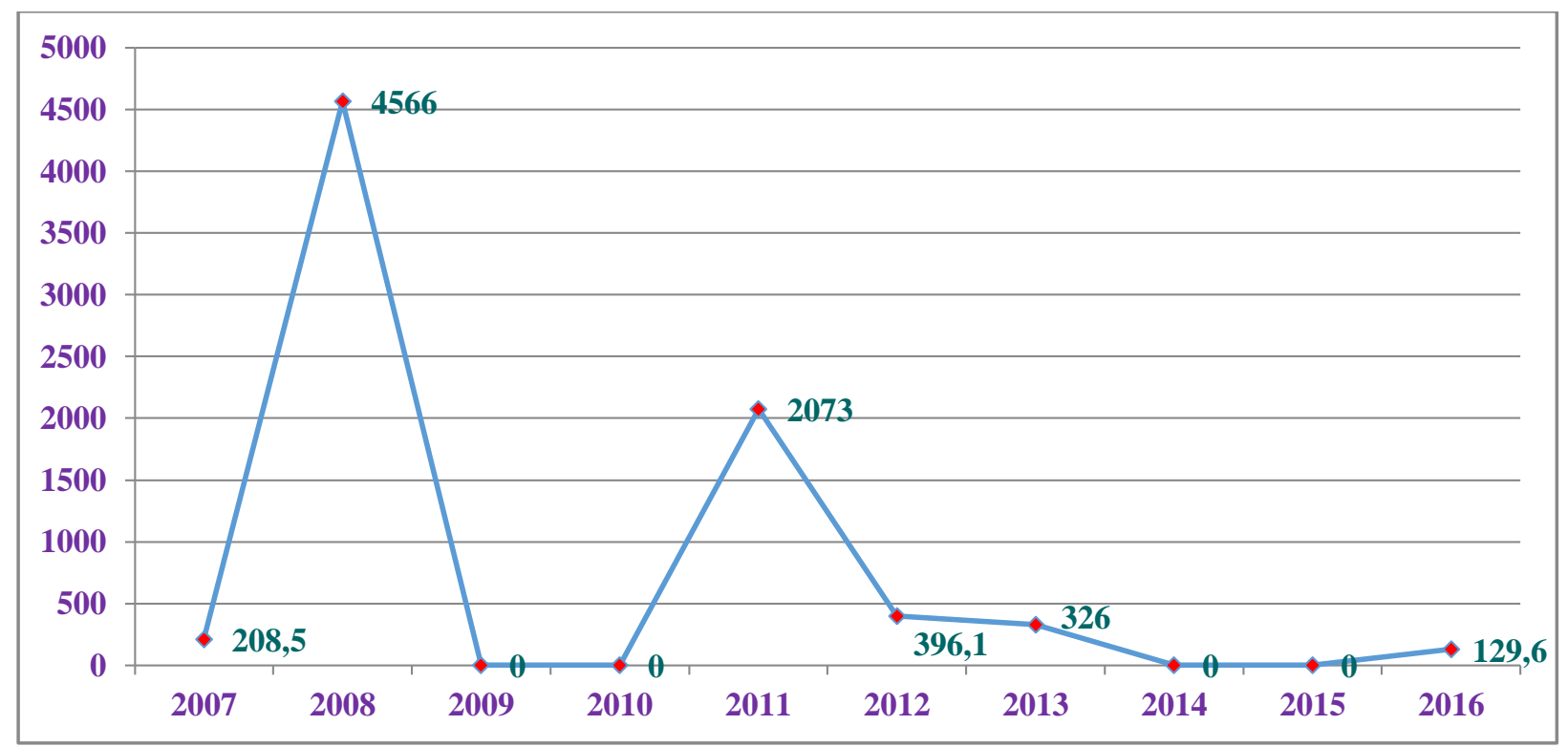

Рисунок 1 - Объем инновационной продукции в 2007-2016 годы в добывающей промышленности (включая нефтяной сектор), тыс. манат (Подготовлено автором на основе статистических данных Государственного Статистического Комитета Азербайджанской Республики http://www.stat.gov.az).

Отметим, что в переработывающей сфере нефтяной промышленности объем инновационной продукции за 2007-2016 годы составил лишь 498,1 тыс. манатов.
На Рисунке 2 дан объем совершенствования инновационной продукции в нефтедобывающей промышленности (включая нефтяной сектор).

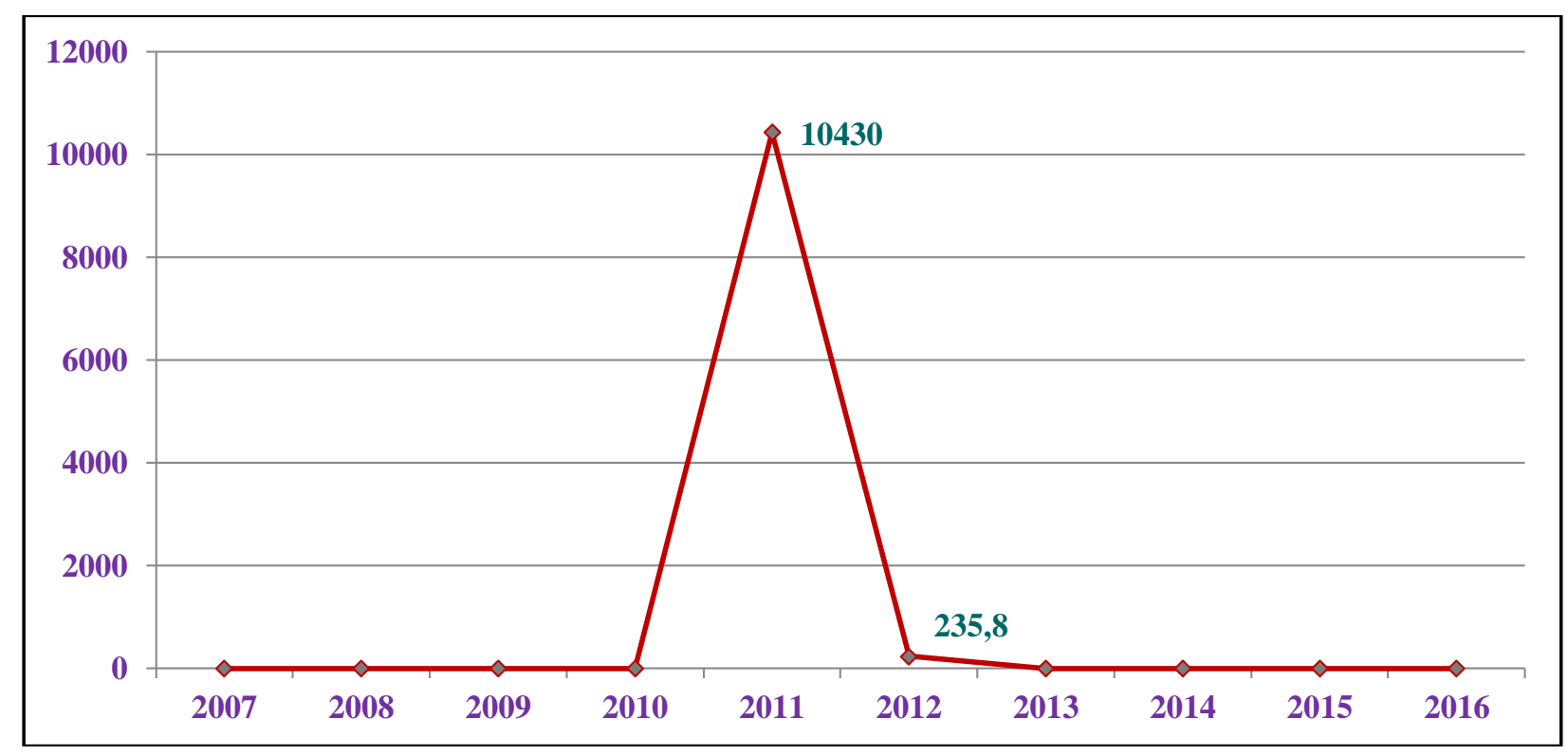

Рисунок 2 - Объем совершенствования инновационной продукции в нефтедобывающей промышленности (включая нефтяной сектор) Азербайджанской Республики за 2007-2016 годы, тыс. манат (Подготовлено автором на основе статистических данных Государственного Статистического Комитета Азербайджанской Республики.http://www.stat.gov.az). 


\begin{tabular}{|c|c|c|c|c|c|c|}
\hline \multirow{4}{*}{ Impact Factor: } & ISRA (India) & $=1.344$ & SIS (USA) & $=0.912$ & ICV (Poland) & $=6.630$ \\
\hline & ISI (Dubai, UAF & $=0.829$ & РИНЦ (Russia) & $=0.207$ & PIF (India) & $=1.940$ \\
\hline & GIF (Australia) & $=0.564$ & ESJI (KZ) & $=4.102$ & IBI (India) & $=4.260$ \\
\hline & JIF & $=1.500$ & SJIF (Morocco & $=2.031$ & & \\
\hline
\end{tabular}

За период с 2007 по 2016 годы в Азербайджане по выпуску нефтяных продукций объем совершенствования инновационных продукций в целом составил лишь 1717 тыс. манатов и основной выпуск этой продукции приходится на 2010 год.
На Рисунке 3 даны расходы на технологические инновации по инновационным категориям в нефтедобывающей промышленности (включая нефтяной сектор) в 2005-2016 годы.

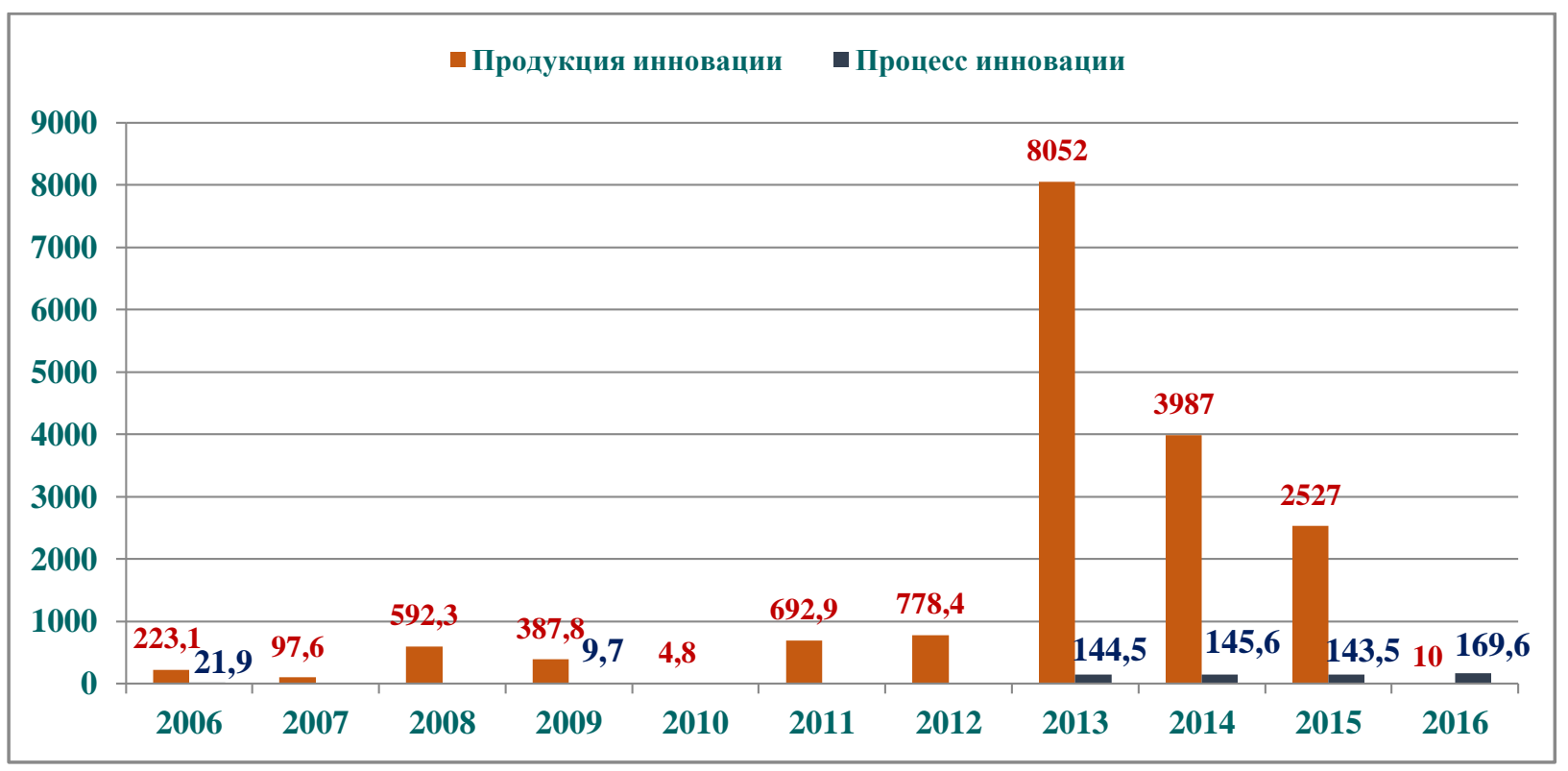

Рисунок 3 - Расходы на технологические инновации по инновационным категориям в нефтедобывающей промышленности (включая нефтяной сектор) в 2005-2016 годы, тыс. манат (Подготовлено автором на основе статистических данных Государственного Статистического Комитета Азербайджанской Республики. http://www.stat.gov.az).

Как видно, расходы на технологические инновации находятся на низком уровне и ожидать положительные сдвиги в развитии уровня инновационной технологии, создании новой инновационной продукции сложно и затруднительно и представляется.
На Рисунке 4 отражен объем расходов на технологические инновации, по производству нефтяной продукции исходя из типов инновации в Азербайджане за 2005-2016 годы. 


\begin{tabular}{l|lr|ll|ll} 
& ISRA (India) & $=\mathbf{1 . 3 4 4}$ & SIS (USA) & $=\mathbf{0 . 9 1 2}$ & ICV (Poland) & $=\mathbf{6 . 6 3 0}$ \\
Impact Factor: & ISI (Dubai, UAE) $=\mathbf{0 . 8 2 9}$ & PUHЦ (Russia) $=\mathbf{0 . 2 0 7}$ & PIF (India) & $=\mathbf{1 . 9 4 0}$ \\
& GIF (Australia) & $=\mathbf{0 . 5 6 4}$ & ESJI (KZ) & $=4.102$ & IBI (India) & $=\mathbf{4 . 2 6 0}$ \\
& JIF & $=\mathbf{1 . 5 0 0}$ & SJIF (Morocco) & $=\mathbf{2 . 0 3 1}$ & & \\
\hline
\end{tabular}

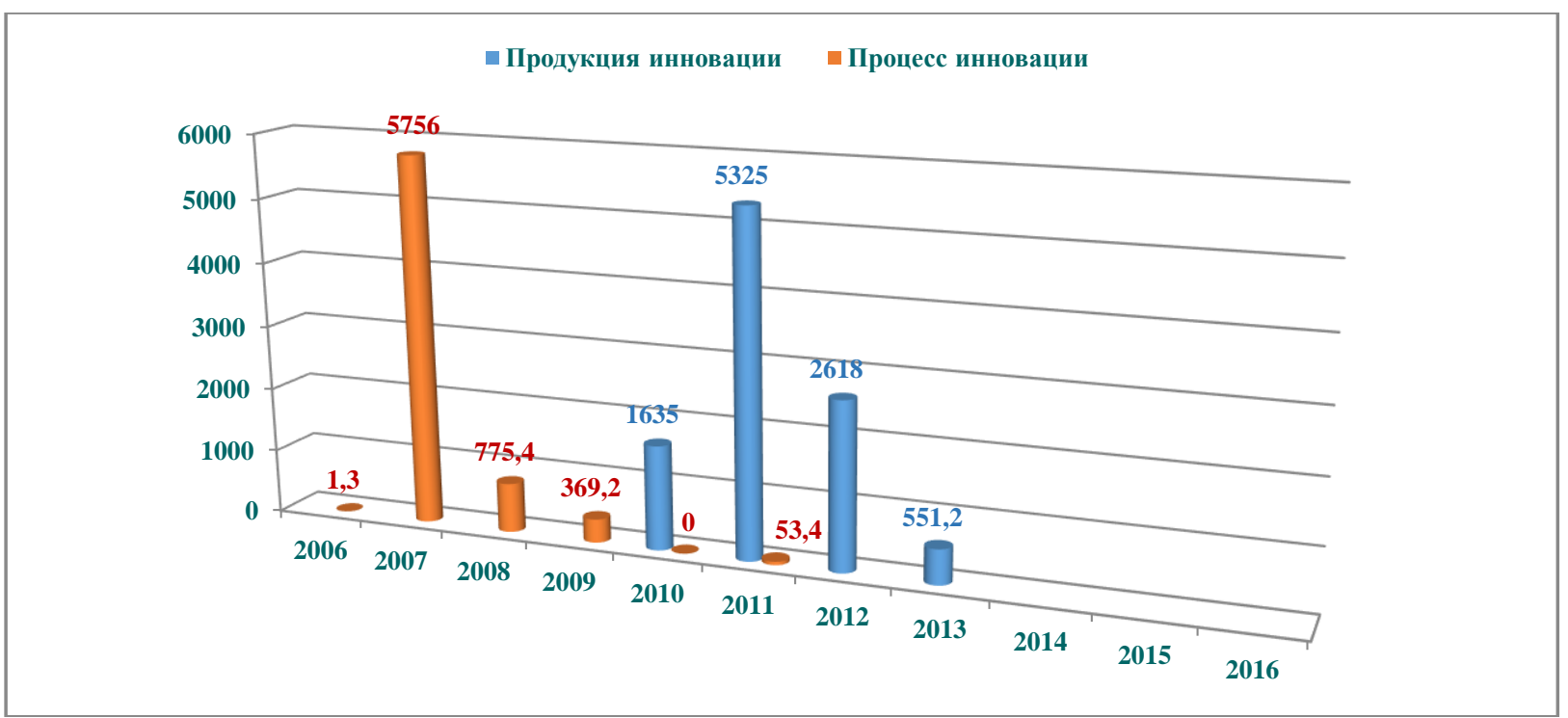

Рисунок 4 - Объем расходов на технологические инновации, по производству нефтяной продукции исходя из типов инновации в Азербайджане за 2005-2016 годы.тыс. манат(Подготовлено автором на основе статистических данных Государственного Статистического Комитета Азербайджанской Республики.http://www.stat.gov.az).

Отметим, что по этому направлению средства, вложенные на технологические инновации находяться на мизерном уровне.

На Рисунке 5 даны расходы на технологические инновации в добывающей промышленности (включая нефтяной промышленность) по видам деятельности и источником финансов в Азербайджане за 20052016 годы.

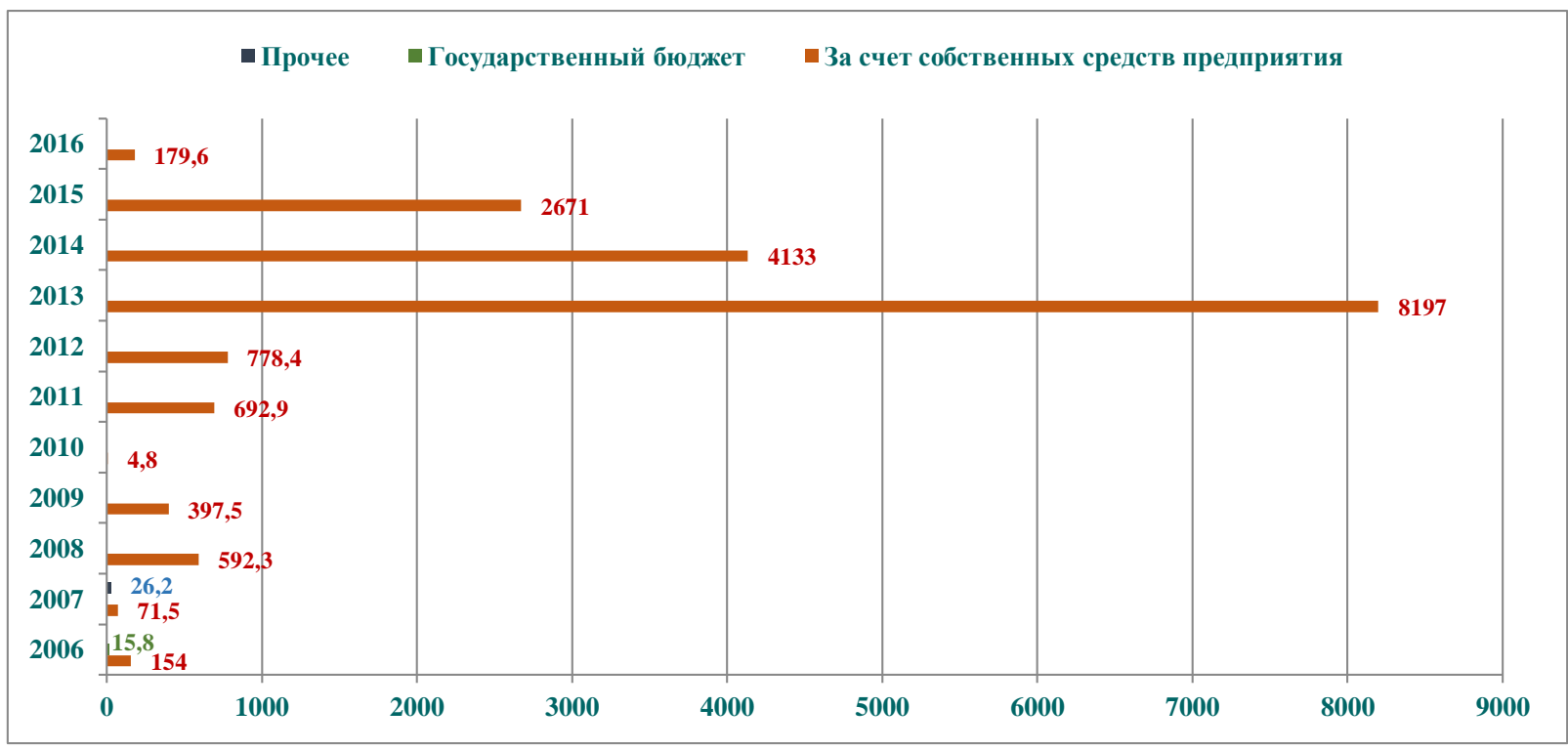

Рисунок 5. Расходы на технологические инновации в добывающей промышленности (включая нефтяной промышленность) по видам деятельности и источником финансов в Азербайджане за 2005 2016 годы, тыс. манат (Подготовлено автором на основе статистических данных Государственного Статистического Комитета Азербайджанской Республики. http://www.stat.gov.az).

Как видно из Рисунка 5 расходы на технологические инновации в основном организованы за счет собственных средст предприятия и средства из государственного бюджета отсутсвуют, а объем иностранных инвестиций слишком мал.

На Рисунке 6 отражены расходы на технологические инновации по видам

ISPC Generalization of scientific results, 
деятельности и внедрения за 2011-2016 годы в

Азербайджане.

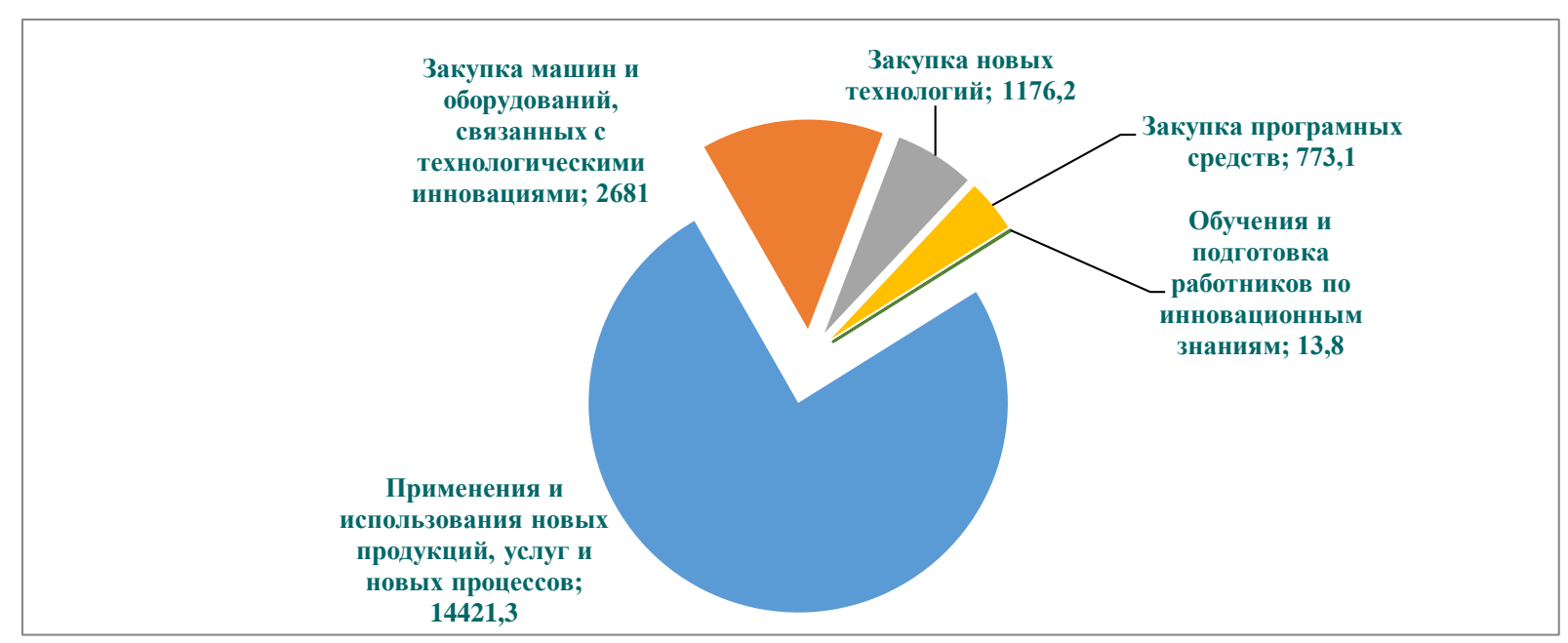

Рисунок 6 - Расходы на технологические инновации по видам деятельности и внедрения за 2011-2016 годы в Азербайджане, тыс. манат (Подготовлено автором на основе статистических данных

Государственного Статистического Комитета Азербайджанской Республики. http://www.stat.gov.az).

\section{Conclusion}

Можно отметить, что расходы на технологические инвестиции в добывающей промышленности (включая нефтяную промышленность) неадекватны потенциалу этой сферы в Азербайджане.

В целом, осуществление данных мероприятий могло бы дать эффективное влияние на совершенствование организационноэкономического механизма инновационного предпринимательства и его управление в нефтяной промышленности Азербайджана:

- В первую очередь, с учетом накопленного опыта по подготовке и осуществлению нефтегазовых контрактов, необходимо активизировать процессы привлечения инноваций и развития предпринимательства в нефтяной промышленности страны;

- Остается актуальным усиление законодательной базы инновационной деятельности в стране;

- Нуждается в интенсификации развития частное предпринимательство и рассмотрении в рамках целевых программ по организации деятельности инновационных направлений в нефтяной промышленности Азербайджана в современных условиях и т.д.

\section{References:}

1. Belokrylova O.S. (2009) Teoriya innovatsionnoy ekonomiki. Rostov n/D: Feniks, 2009, 376 p.

2. Gasymov F.KH., Nadzhafov Z.M. (2009) Innovatsii: sozdaniya, raspredeleniya, prespektivy razvitiya. Baku: Nauka, 2009.- 231

p.
3. Atakishiyev M., Suleymanov G. (2004) «Innovatsionnyy menedzhment», Baku: 2004.

4. Vasil'yev V.P. (2011) Upravleniye innovatsiyami. - Moscow: Delo i servis, 2011$224 \mathrm{p}$. 


\begin{tabular}{|c|c|c|c|c|c|c|}
\hline Impact Factor: & $\begin{array}{l}\text { ISRA (India) } \\
\text { ISI (Dubai, UAE } \\
\text { GIF (Australia) } \\
\text { JIF }\end{array}$ & $\begin{array}{l}=1.344 \\
=0.829 \\
=0.564 \\
=1.500\end{array}$ & $\begin{array}{l}\text { SIS (USA) } \\
\text { PИНЦ (Russia) } \\
\text { ESJI (KZ) } \\
\text { SJIF (Morocco) }\end{array}$ & $\begin{array}{l}=0.912 \\
=0.207 \\
=\mathbf{3 . 8 6 0} \\
=\mathbf{2 . 0 3 1}\end{array}$ & $\begin{array}{l}\text { ICV (Poland) } \\
\text { PIF (India) } \\
\text { IBI (India) }\end{array}$ & $\begin{array}{l}=6.630 \\
=1.940 \\
=4.260\end{array}$ \\
\hline
\end{tabular}

5. Paley T.F. (2011) Innovatsionnyy menedzhment. - Kazan': Izd-vo «Foliant'», 2011. - 162 p.

6. Mel'nikov A.V. (2014) Organizatsionnoekonomicheskiy mekhanizm obespecheniya innovatsionnogo razvitiya neftyanoy otrasli. Diss. kand. ekon. nauk. Sankt-Peterburg, 2014.$155 \mathrm{p}$.

7. Gasymov F.KH., Aliyev T.N. (2013) Organizatsiya i upravleniya natsional'noy innovatsionnoy sistemy. Nauka i Obrazovaniya, Baku, 2013.

8. (2000) Innovatsii: teoriya, mekhanizm, gosudarstvennoye regulirovaniye. / Podred. YU.V. Yakovtsa. - M.: RAGS, 2000. - 237 p

9. (2000) Osnovy innovatiki. / Pod red. N.Z. Sultanova. - Orenburg: OGU, 2000.- 172 p.

10. Porter M.Ye. (2005) Konkurentnoye preimushchestvo. Kak dostich' vysokogorezul'tata i obespechit' yego ustoychivost'. - Moscow: Al'pina Biznes Buks, 2005. - $715 \mathrm{p}$.

11. Filosofova T.G. (2008) Konkurentsiya. Innovatsii. Konkurentosposobnost'. - Moscow: YUNITI-DANA, 2008.
12. Chezbro G. (2007) Otkrytyye innovatsii. Moscow: Pokoleniye, 2007. - 336 p.

13. Nadzhafov Z.M. (2011) Formirovaniya i razvitiya natsional'noy innovatsionnoy sistemy v Azerbaydzhanskoy Respublike. Avtoreferat diss. d-ra ekon. nauk. Baku, 2011.- 35 p.

14. Musayev A. (2014) Innovatsionnaya ekonomika i nalogovaya stimulirovaniya. Baku, 2014.

15. Muradverdiyeva L.A. (2012) Innovatsionnyye vyzovy razvitiya neftyanoy promyshlennosti // Kreativnaya ekonomika. - 2012. № 12. - p. 8287.

16. Guseynova A.D. (2017) Puti razvitiya innovatsionnoy deyatel'nosti v Azerbaydzhane// Azerbaydzhanskiy Nalogovyy Zhurnal, №4 (124), 215 p. 129-144.

17. Mamedova E.G., Mirgeydarova A.I. (2017) O sovershenstvovanii innovatsionnoy deyatel'nosti v neftegazodobyvayushchey otrasli promyshlennosti Azerbaydzhana // Vestnik VGU, seriya: ekonomika i upravleniye, №2, 2017.-p. 25-29. 